\title{
What happens when the assumptions underlying our commitment to free speech no longer hold?'
}

\author{
Richard Moon ${ }^{\star}$
}

\section{The Underlying Assumptions}

A commitment to freedom of expression means that an individual must be free to speak to others and to hear what others may say, without interference from the state. It is said that the answer to bad or erroneous speech is not censorship, but rather more and better speech. Importantly the listener, and not the speaker, is seen as responsible (as an independent agent) for his or her actions, including harmful actions, whether these actions occur because he or she agrees or disagrees with the speaker's message. In other words, respect for the autonomy of the individual - whether as speaker or listener - means that speech is not ordinarily regarded as a 'cause' of harmful action. A speaker does not 'cause' harm simply because she or he persuades the audience of a particular view and the audience acts on that view in a harmful way.

Underlying this commitment to freedom of expression (and the refusal to treat speech as a 'cause' of subsequent harm) is a belief that humans are substantially rational beings, capable of evaluating factual and other claims, and an assumption that public discourse is open to a wide range of competing views that may be assessed by the audience. The claim that 'bad' speech should not be censored, but instead answered by 'better' speech, depends on both of these assumptions the reasonableness of human judgment and the availability of competing perspectives. A third, but less obvious, assumption underpinning the protection of freedom of expression is that the state has the effective power to either prevent or punish harmful action by the audience. Individuals will sometimes make poor judgments. The community's willingness to bear the risk of such errors in judgment may depend on the state's ability to prevent the harmful actions of audience members or at least to hold audience members to account for their actions.

Expression cannot be restricted by the state simply because it might persuade its audience to act in a harmful way or because it might negatively affect an individual's or group's self-understanding or self-esteem. The courts, in Canada and elsewhere, though, recognize that these assumptions about the audience's agency or judgment that underlie the protection of speech may not always hold (and indeed never hold perfectly). Prohibitions on false or misleading product claims have been supported because advertisers have overwhelming power in the 'marketplace of ideas' and information (so that others have limited opportunities to correct misleading ads) and because so much commercial advertising is non-rational or visceral in its appeal. Similarly, the restriction of defamatory speech rests on a recognition that false claims made about an individual are not easily corrected through 'more speech.' The harm of defamatory speech may persist, because the audience is not always in a position to assess the false and damaging claims 
and because (people being as they are) the correcting speech may not spread as effectively as the original defamation.

\section{Exceptional Circumstances}

Freedom of expression doctrine has always permitted the restriction of expression that occurs in a form and/or context that discourages independent judgment by the audience or that impedes the audience's ability to assess the claims made. When speech 'incites' or 'manipulates' the audience to take violent action, the speaker may be seen as responsible for, and perhaps even as a participant in, any violence that follows. For example, in On Liberty J. S. Mill thought that the authorities would be justified in preventing a fiery speech given near the home of a corn merchant to a crowd of farmers angry about crop prices. ${ }^{2}$ A heated speech delivered to a 'mob' appeals to passion and prejudice and might lead to impulsive and harmful actions. Speech is described as incitement when the time and (reflective) space between the speech and the (called -for) action is so limited that the speaker may be viewed as leading the audience into action and not simply as trying to persuade them into taking action.

In American free speech jurisprudence, the classic example of a failure in the conditions of ordinary discourse comes from a judgment of Justice Holmes, who said that "The most stringent protection of free speech would not protect a man in falsely shouting fire in a theatre and causing a panic." 3 The false yell of fire in a crowded theatre represents a clear deviation from the conditions of ordinary speech. The theatre audience in such a case would not have time to stop and think before acting on the communicated message. The panic that would follow the yell of fire in these circumstances would almost certainly result in injury

The examples given by Mill and Holmes involve circumstances that limit the audience's ability to carefully or dispassionately assess the communicated message. The assumption is that ordinarily, when an individual communicates with others, he or she appeals to their independent and reasoned judgment. In exceptional cir- cumstances, however, an individual's words may appeal to passions and fears and may encourage unreflective action. In these circumstances, the state may be justified in restricting expression. Speech may be treated as a cause of audience action when the time and space for independent judgment are compressed, or when emotions are running so high that audience members are unlikely to stop and reflect on the claims being made. While the line between rational appeal or conscious argument, on the one hand, and on the other, manipulation or incitement may not be easy to draw (and indeed is a relative matter), it is at least possible to identify some of the circumstances or conditions in which reasoned judgment is constrained.

\section{Systemic Changes}

What happens, though, when the basic assumptions underlying the commitment to freedom of expression - about the rationality of discourse and the scope of communicative engagement - are eroded or undermined not simply in limited situations, of the sort described by Mill and Holmes, but instead by more systemic changes in the character of modern public discourse? In the last half of the twentieth century, two developments in the structure and character of public discourse raised significant challenges for freedom of expression doctrine. ${ }^{4}$ The first was the rise of commercial advertising, a form of speech that seemed to be designed to influence its audience non-cognitively (the problem of manipulation). The problem was not just that commercial advertising seemed to be everywhere, but more significantly, that it became the model for other forms of expression, including political speech. ${ }^{5}$ The second was the domination of public discourse by a smaller group of speakers and a narrower range of perspectives - resulting from the concentration of media ownership and the high cost of access to the media (the problem of unequal access).

While 'manipulation' and 'inequality' are often described and responded to as separate problems, they may be viewed as two aspects or dimensions of the much larger problem of the domination of public discourse by commercial 
messages and the advertising form. Commercial advertisements have a manipulative impact only because they so completely dominate public discourse. The overwhelming number of commercial messages that we are confronted with each day reduces the space for critical viewing of individual ads. There are so many ads that it is simply not possible for the audience to reflect on the claims or associations of each. These ads simply wash over us. The domination of public discourse by advertising also means that the unnatural images or absurd associations of a particular ad seem unexceptional. Because the principal channels of public discourse have been controlled by commercial interests and carry only ads and advertising-funded programming, the underlying message of advertising, that selfrealization is achieved through consumption, is an almost unchallengeable cultural assumption.

Concern that certain messages may dominate discourse and overwhelm or displace other views is more explicit in the debate about the regulation of political or campaign advertising. Inequality in election spending, though, is a problem because of the 'advertising' form of most campaign expression, which is composed of images and slogans with little evaluative content. Election spending limitations, which do not restrict the message or form of expression but only the amount of money that can be spent in support of a particular message, are supported on the ground that unlimited spending will allow the messages of some candidates to 'drown out' those of other candidates. How is it, though, that the message of the better-financed candidate 'drowns out' the message of his or her competitors? The competitor's message can still be heard, even if less often. If greater volume has an impact (if repetition of messages makes a difference), it is because so much contemporary political discourse has adopted the form of commercial advertising, seeking to influence the audience emotionally or non-cognitively.

Restrictions aimed at either the manipulative impact of expression or the dominance of particular messages are partial, or symptom, responses to a systemic problem. Inequality in election spending is a problem because of the 'advertising' form of most campaign expression, which is composed of images and slogans with little evaluative content. Commercial advertisements have a manipulative impact only because they so completely dominate public discourse. Yet the courts in Canada, and elsewhere, have treated manipulation and inequality as separate problems, each representing a distinct and limited failure in the ordinary operation of public discourse. A commitment to freedom of expression, at least as a judicially-protected constitutional right, rests on a belief that, in the absence of special circumstances, individuals should be permitted to express themselves and to assess the expression of others. Manipulation, then, must be viewed as an identifiable deviation from the ordinary conditions of free and rational public discussion; inequality must be viewed as a particular unfairness in electoral competition that can be addressed by setting basic ground rules that level the 'playing field'

\section{The Internet}

The emergence of the Internet, as a significant conduit for public and personal communication, seemed to lessen public concerns about media concentration and unequal access to communicative resources. The Internet (its many platforms) offers a low-cost way to communicate with a potentially large audience. The Internet is an accessible means of communication that has enabled different individuals, with similar concerns, to connect and organize, but it has also contributed significantly to audience fragmentation. And so, while it might be said that more views are expressed and available through the Internet, it appears that most Internet users expose themselves (or are exposed to) to a relatively narrow range of opinions that tend to reinforce the views they already hold. Despite their failings, newspapers and broadcasters often provided a common space (served as part of a public sphere) where a large and sometimes diverse group of readers or viewers might be exposed to different views.

The Internet is a remarkable source of information that can be easily and quickly accessed. 
Indeed, the accessibility (and formal equality) of the Internet has led many to argue against any form of Internet speech restriction. Yet, at the same time, the Internet seems to be an effective vehicle for speech that appeals to the emotional or visceral and is intended to play on, or reinforce, the audience's prejudices. Moreover, the absence of (traditional media) filters means that groundless assertion and personal attacks are unimpeded. More subtly, the Internet seems to encourage the distorted 'democratic' idea that all opinions are equally worthy of respect - regardless of whether they have any factual grounding. The Internet did not create this commercial/ consumer model of speech and engagement, but it has advanced it considerably. Audience fragmentation (and the 'echo chamber effect'), the absence of filters and systems of accountability, as well as speaker remoteness or anonymity, have contributed to the decline of reason-based argument and thoughtful, respectful, engagement. When there is engagement on an issue, it is often confrontational and uncivil, and not concerned with persuading others or understanding their views. ${ }^{6}$

\section{Speech as Cause?}

What will or should happen to free speech doctrine if the assumptions about the rationality of discourse, and the scope of communicative engagement that underlie our commitment to freedom of expression, continue to be eroded? In Canada, the courts have sometimes upheld limits on freedom of expression without explaining why we should not trust the individual audience member to make his or her own judgment about the merits of the expression. Instead, in these cases, the courts have adopted a behavioural approach - asking simply whether the expression 'causes' harm. ' When defining the scope of freedom of expression, the courts regard the individual as free and rational, as an autonomous agent capable of giving direction to his or her life. In expressing him or herself, an individual gives voice to his or her thoughts and feelings and provides ideas and information for other individuals to consider, and to adopt or reject. However, when the courts move from defining the scope of the freedom (under section 2(b) of the Canadian Charter of Rights and Freedoms) $)^{8}$ to assessing the freedom's limits (under section 1 - the Charter's limitations provision), they seem to shift to a behavioural or causal discourse. In their limitations analysis (section 1), the courts seem to rely on a different image of the individual. The individual is seen as irrational, manipulable, directed by unchosen preferences, urges, and desires. Expression is seen as a form of action that impacts on the individual, sometimes causing him or her harm or sometimes causing him or her to engage in harmful behaviour. When confronted with issues of manipulation, intimidation, and communicative power, the Canadian courts' faith in the freedom and rationality of the individual collapses. This shift to a behavioural discourse at the limitations stage of the courts' analysis occurs without any reconsideration of the assumptions that underlie their initial account of the value and scope of freedom of expression. When expression takes place in a context in which individual judgment seems distorted or constrained, the courts have found it easier to label and treat the expression as a form of action that 'impacts' the individual, rather than to isolate the exceptional character or circumstances of the expression. In addition, because cause is difficult to prove, the courts have either fallen back on "common sense" or deferred to legislative judgment to complete the causal link between expression and harm. ${ }^{9}$

However, if the courts support the restriction of potentially harmful expression without explaining why the judgment of the audience is not to be trusted in the particular circumstance, and without acknowledging the costs of removing certain matters from the scope of public discourse, the right to free expression will have ceased to play any meaningful role in their decision-making. Freedom of expression has little substance if our trust in the 'autonomous' judgment of the individual is the exception (a condition that must be established); it has no substance if it is 'protected' only when we agree with its message or consider its message to be harmless. The problem with this approach to free speech protection - an approach that formally acknowledges the premises of free speech but 
supports limits on speech that carries a 'harmful' message - is that it puts the whole free expression edifice at risk.

But, is the only alternative to carry on as if we live in a world of rational discourse and open engagement? Ignoring these changes in the form and means of public discourse may have considerable costs. This seems to be the approach of the US courts, which have rejected significant limits on election campaign spending, ${ }^{10}$ and hate speech. ${ }^{11}$ But with such an approach, we may end up with a large group of citizens for whom truth no longer matters, and who can be pushed and pulled by populist politics.

\section{Endnotes}

* Distinguished University Professor, and Professor of Law, University of Windsor

1 This paper was presented at the International Bar Assn. Annual Conference, Boston, September 2013 and at St. Joseph's University, Beirut, Lebanon, February 2017. It draws on several earlier publications including Richard Moon, "Limits on Constitutional Rights: The Marginal Role of Proportionality Analysis" (2017) 50:1 Israel LR 49, Richard Moon, Putting Faith in Hate: When Religion is the Source or Target of Hate Speech, (Cambridge, UK: Cambridge University Press, 2018) and Richard Moon, The Constitutional Protection of Freedom of Expression, (Toronto: University of Toronto Press, 2000).

2 John Stuart Mill, On Liberty, ed by Gertrude Himmelfarb (Penguin Classics, 1982) at 119.

3 Schenck v United States, 249 US 47 (1919) at 52.

4 Richard Moon, The Constitutional Protection of Freedom of Expression (Toronto: University of Toronto Press, 2000) at chapter 3 [Moon, Freedom of Expression].

5 Richard Moon, "The Attack on Human Rights Commissions and the Decline of Public Discourse" (2010), 73 Sask L.R. 93 at 123. [Moon, "The Attack on Human Rights Commissions"]. (From the Annual Saskatchewan Law Review Lecture, 2010): "Commercial advertising has come to dominate public discourse, not just in the sense that so much of that discourse is comprised of ads (we see ads everywhere), but also in the way in which these ads have become the general model for public expression, for how political and other public actors convey their views and seek to persuade others. Political speech in the commercial model seeks an emotional or visceral response, eschews complexity and nuance, and devalues factual accuracy. The dominance of the advertising model has made it increasingly difficult for us to envision political speech that seeks to persuade citizens of the wisdom of a particular policy rather than simply shape or manipulate the concerns and feelings of political consumers." "Political spin inverts the relationship between fact and opinion, with the former often following the latter. To the political spinner, facts are just supports or props for a position. "Facts" may be selected, massaged, and even invented to advance a larger truth or simply the self-interest of the speaker."

6 Moon, "The Attack on Human Rights Commissions" note 5 at 129: Spin is political speech that follows the model of commercial advertising. "It will not advance democratic engagement or meaningful discussion of public policy, and it cannot bring about consensus or compromise or even respectful disagreement based on an awareness of the costs and benefits of the different responses. Spin encourages the fragmentation of the civic audience into insular ideological communities that are unable to engage with each other. The costs of spin are even more fundamental than this though. Spin degrades public discourse, so that we no longer expect to be told the truth and are no longer able to evaluate positions based on the accuracy of their claims or assumptions."

7 Moon, Freedom of Expression, supra note 4 at chapter 2.

8 s 7, Part 1 of the Constitution Act, 1982, being Schedule B to the Canada Act 1982 (UK), 1982, c 11 [Charter].

9 See e.g., Harper $v$ Canada (AG), 2004 SCC 33.

10 Citizens United $v$ Federal Election Commission, 558 US 310 (2010).

11 RAV v St Paul (City of), 505 US 377 (1992). 
